\title{
Pathological Aspects of a Subclinical Marek's Disease Case in Free-Range Chickens
}

http://dx.doi.org/10.1590/18069061-2015-0001

Technical Note

-Author(s)

\author{
Abreu DLC' \\ Santos FF" \\ José DS"II \\ Tortelly RIV \\ Nascimento $\mathrm{ER}^{\prime}$ \\ Pereira VLA
}

Department of Collective Animal Health and Public Health, School of Veterinary Medicine, Universidade Federal Fluminense (UFF), RJ, Brazil

" Post-graduationprogram in Veterinary Medicine (Ph.D.) - Veterinary Hygiene and Processing of Animal Products, School of Veterinary Medicine, UFF

III DepartmentofVeterinaryPathologyand Medicine, School of Veterinary Medicine, UFF

Iv Undergraduatestudent, School of Veterinary Medicine, UFF

\section{Mail Address}

Corresponding author e-mail address Dayse Lima da Costa Abreu

Departamento de Saúde Coletiva Veterinária e Saúde Pública, Faculdade de Veterinária Universidade Federal Fluminense - UFF. Rua Vital Brasil Filho, ${ }^{\circ} 64$, Vital Brazil, Niterói, RJ, Brazil. CEP 24230-340

E-mail: dayseabreu@id.uff.br

\section{- Keywords}

Marek's Disease, Histopathology, free-range chickens.

\section{ABSTRACT}

The present report aims at describing the occurrence of Marek's Disease (MD) in a free range poultry farm based on macroscopic and microscopic lesions. For this purpose, seven free-range chickens were evaluated by gross and microscopic examination. Tumor lesions were observed in the liver and ovary, in addition of enlarged kidney and spleen, skin thickening and whitish lesions in streak form in the breast muscle. Fragments of the affected organs were collected and placed in $10 \%$ formalin for processing by the usual histopathology techniques, and stained with hematoxylin-eosin. Under microscopic evaluation, we observed pleomorphic populations of neoplastic lymphoreticular cells with pyknotic nuclei in the same organs, all compatible with MD. The macroscopic and microscopic lesions presented in this study were consistent with $M D$, meaning that the MD virus is present in the rearing environment of the studied chicken farm.

\section{INTRODUCTION}

The health control of poultry reared free-range systems is less strict than that of commercial flocks, increasing the risk of disease outbreak. Fossum et al. (2009) reported significant differences in the health of poultry reared under different husbandry systems. The authors detected more health problems in poultry kept in alternative systems as compared to conventional commercial establishments, with a high prevalence of bacterial diseases. Among viral diseases, Marek's disease (MD) was diagnosed only in flocks in alternative systems.

MD is caused by an alpha-herpesvirus, whose virulence is associated with its ability to induce lymphoproliferative lesions. These lesions are characterized by enlargement of the peripheral nerves due lymphocytic infiltration and by the presence of lymphomas in various visceral organs and tissues, which may be present even in vaccinated birds (Buscaglia et al., 2004; Witter et al., 2005). MD can be manifested in the affected chickens as early mortality in the absence of gross or microscopic lesions; depression, pale crest, reduced feed intake and weight gain, ataxia, and paralysis (Buscaglia et al., 2004).

The clinical expression of MD and the presence of lymphomas are influenced by the immune response, which may be influenced by genetic factors. Buscaglia et al. (2004) inoculated vaccinated SPF chickens with $M D$ virus serotypes characterized as very virulent (vVMDV) and very virulent plus ( $v v+M D V)$, and detected a high incidence of the disease in susceptible chicken strains, but not in chickens genetically resistant to the MD virus. Resistant chicken strains tend to maintain the virus latent, while in susceptible chickens the infection causes lymphomas (Burgess et al., 2001; Kaiser et al., 2003). 
Bird age at the time of virus exposure may also influence the disease expression. Chickens of all ages are susceptible to infection, but the frequency of lymphomas is lower in older birds, especially in more resistant strains (Witter et al., 1973).

At necropsy, MD gross lesions are characterized by diffuse enlargement of the liver and the spleen, presence of lymphomas in liver, kidney, ovary, proventriculus, spleen, lungs, nerves, heart, skin, and atrophy of the bursa of Fabricius and thymus. The histopathology of affected organs shows a marked cellular polymorphism, with the presence of lymphocytes, lymphoblasts, fibroblasts and infiltration of tumor cells arranged in circumscribed or diffuse form. In the liver, these lesions are accompanied by degeneration and necrosis of parenchymal liver cells, atrophy of the hepatic ducts and vacuolization (Buscaglia et al., 2004; Witter et al., 2005). Necrosis and destruction of lymphoid cells are described in the thymus and bursa of Fabricius (Buscaglia et al., 2004; Fodor et al., 2011). Lymphomas can be found in the absence of any nerve injury or clinical signs, and therefore it may go unnoticed during rearing or even at processing. Gross lesions may also be dubious, and do not confirm the presence of $M D$, demanding the microscopic examination of the lesions for their proper characterization (Vieira-Pinto et al., 2003), as well as for the differential diagnosis with other neoplasms or diseases causing enlargement of the peripheral nerves (Schat \& Nair, 2008).

The present report aims at describing the occurrence of $\mathrm{MD}$ in a free-range chicken farm, characterized by the absence of clinical manifestations and diagnosed by the evaluation of gross and microscopic lesions.

\section{MATERIAL AND METHODS}

The poultry farm studied is dedicated to rearing broilers and laying hens under an extensive system. It is located in the municipality of Carapebus, state of Rio de Janeiro, Brazil. The farm stock is of 10,000 birds, divided into six layer flocks and five broiler flocks. It is not near other poultry farms, commercial or not.

The affected birds had been vaccinated against MD at the first day of age, and were approximately 50 weeks of age. No obvious clinical signs of MD were observed, but multiple whitish nodules were detected in the viscera during processing. Based on these findings, seven birds were selected, euthanized by atlanto-occipital dislocation, and necropsied. Fragments of affected organs were placed in recipients containing $10 \%$ formalin for processing by the usual histopathology techniques, according to Luna (1968), and slides were stained by hematoxylin-eosin and examined under an optical microscope (Bioval L200A, Brazil).

\section{RESULTS AND DISCUSSION}

All seven necropsied chickens presented tumor lesions in the liver. Splenomegaly, spleen discoloration, enlarged kidneys, tumors in atrophic ovaries and focal whitish thickening of the skin were also observed. In one chicken, lesions in the form of streaks were observed on the breast muscle, which gave to the organ a "boiled" appearance (Figure 1). Gross lesions, despite being very characteristic of $M D$, were also submitted to histopathological examination for MD confirmation and exclusion of diseases with similar characteristics, such as avian leucosis (Schat \& Nair, 2008).
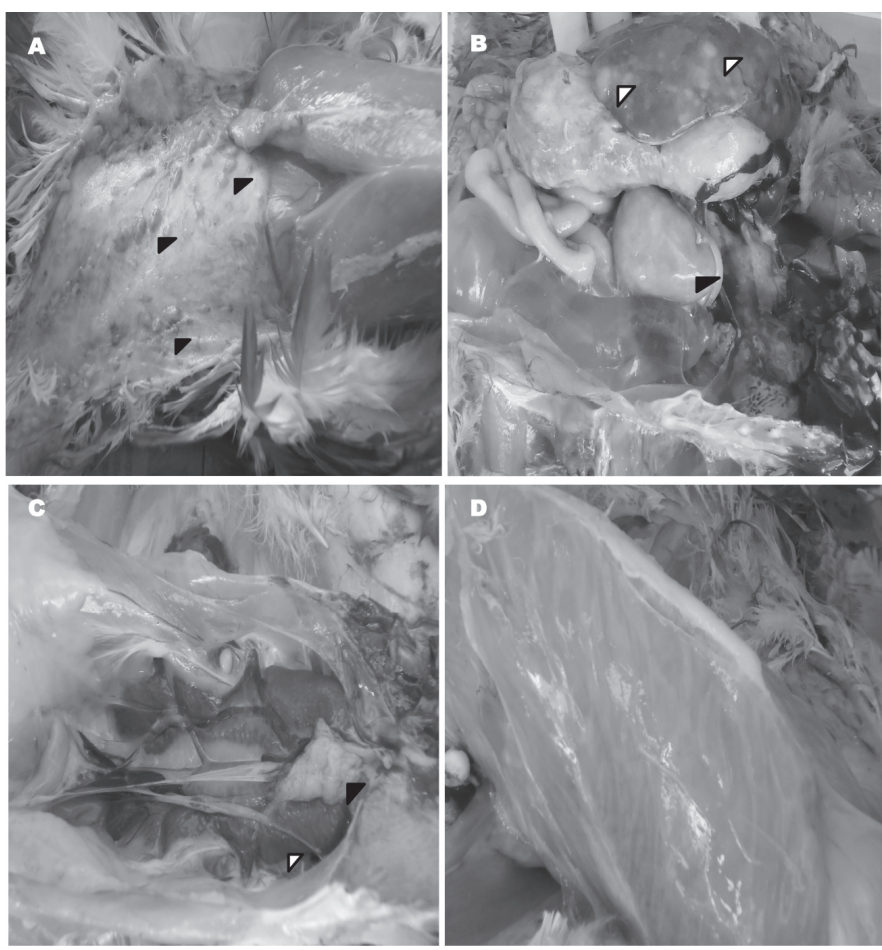

Figure 1 - Gross lesions consistent with Marek's Disease in chickens. A. Multiple cutaneous nodules of varying diameters with whitish aspect (black arrows). B. Splenomegaly with difuse discoloration of the parenchyma (black arrow) and nodular formations in the liver (white arrows). C. Nodular and diffuse formations in immature ovary (black arrow), and diffuse enlargement of the kidneys (white arrow). D. Whitish strips on the breast muscle.

Under the histopathology, spleen and liver presented neoplastic cells and, at higher magnification, pleomorphic populations of neoplastic lymphoreticular cells with pyknotic nuclei (Figure 2) were observed. The gross and microscopic lesions described in this figure are compatible with MD and similar to those described 
by Buscaglia et al. (2004) and Fodor et al. (2011) in studies with chickens infected with the MD virus. Vieira-Pinto et al. (2003) suggests that histopathology, even in the presence of conclusive gross lesions, should be use to confirm the diagnosis of MD.

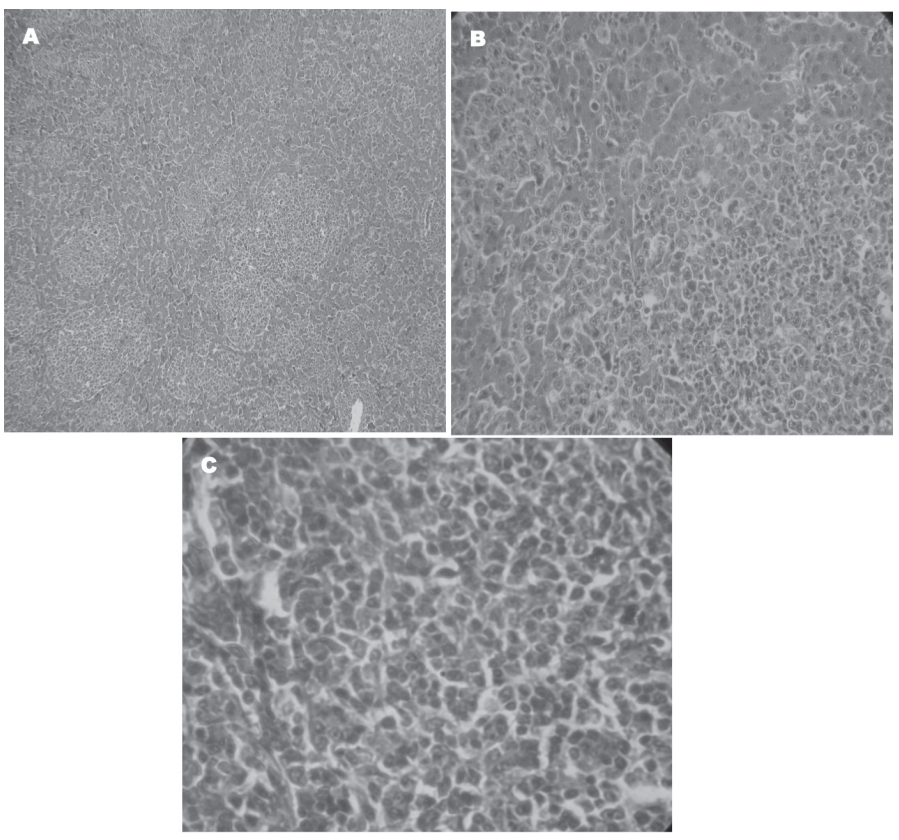

Figure 2 - Microscopic lesions consistent with Marek's disease in chickens. A. Liver. Multiple nests of oncocyts with heterogeneous aspect. HE 10x. B. Liver. Higher magnification of one oncocyt nest. Heterogeneous aspect of lymphoreticular organ invasion with hepatocyte dissociation, HE 40x. C. Spleen. Lymphoreticular infiltrate of neoplastic cells. HE100x

The occurrence of MD, even in vaccinated birds, may be due to poor biosecurity conditions, which are frequently observed in free-range facilities (Fossum et al., 2009). The presence of a highly pathogenic MD virus strain or chick vaccination failure, as well as chicken strains with low genetic resistance to MD, are also considered risk factors (Burgess et al., 2001; Kaiser et al., 2003; . Buscaglia et al., 2004). Vaccination against MD may delay the onset of illness (Buscaglia et al., 2004), which could explain the occurrence of MD in the 50-week-old birds in the present study. Injuries caused by the MD virus progress slowly (Witter et al., 1973), which supports the low mortality rates observed in the studied farm.

The gross and microscopic lesions detected in this study are consistent with MD, indicating that the $\mathrm{MD}$ virus is present in the rearing environment of the studied farm. Effective vaccination, changing the current genetic strains, and improving biosecurity measures are required to eradicate the virus from the farm. We emphasize the purchase of replacement birds, because these are necessarily vaccinated against $\mathrm{MD}$ in the hatchery. The absence of nearby commercial flocks ensures that the presence of the disease does not constitute a risk to poultry production in the state of Rio de Janeiro, Brazil.

\section{REFERENCES}

Burgess SC, Basaran BH, Davison TF. Resistance to Marek's Disease Herpesvirus-induced lymphoma is multiphasic and dependent on host genotype. Veterinary Pathology 2001;38(2):129-142

Buscaglia C, Nervi P, Risso M. Characterization of four very virulent Argentinian strains of Marek's disease virus and the influence of one of those isolates on synergism between Marek's disease vaccine viruses. Avian Pathology 2004;33(2):190-195.

Luna LG. Manual of the histologic staining methods of the armed forces institute of pathology. 3rd ed. New York: McGraw Hill; 1968.

Fossum O, Jansson DS, Etterlin PE, Vågsholm I. Causes of mortality in laying hens in different housing systems in 2001 to 2004. Acta Veterinaria Scandinavica 2009;51(3) [cited 2014 Apr 24]. Available from: http:// www.actavetscand.com/ content/51/1/3.

Fodor I, Coman M, Cătană N. An outbreak of Marek's disease in broiler chickens: epidemiological, clinical and anatomopathological aspects. Lucrari Stiintifice Medicina Veterinaria 2001;42(1):129-142.

Kaiser P, Underwood G, Davison F. Differential cytokine responses following Marek's disease virus infection of chickens differing in resistance to Marek's disease. Journal of Virology 2003;77(1):762-768.

Schat KA, Nair V. Marek's disease. In: Saif YM, Fadly AM, Glisson JR McDoulgald LR, Nolan LK, Swayne DE, editors. Diseases of poultry. 12th ed. lowa: Blackwell Publishing; 2008. p.452-514.

Vieira-Pinto M, Mateus T, Seixas F, Fontes MC, Martins C. O papel da Inspeção sanitária post mortem em matadouro na detecção de lesões e processos patológicos em aves. Quatro casos de lesões compatíveis com a doença de Marek em carcaças de aves rejeitadas. Revista Portuguesa de Ciências Veterinárias 2003;98(547):145-148.

Witter RL, Calnek BW, Buscaglia C, Gimeno IM, Schat KA. Classification of Marek's disease viruses according to pathotype: philosophy and methodology. Avian Pathology 2005;34(2):75-90.

Witter RL, Sharma JM, Solomon JJ, Champion LR. An age-related resistance of chickens to Marek's disease: some preliminary observations. Avian Pathology 1973;2(1):43-54. 
